\title{
Geographic distribution of COPD prevalence in the world displayed by Geographic Information System maps
}

\begin{abstract}
To the Editor:
Existing data on chronic obstructive pulmonary disease (COPD) prevalence are irregularly distributed around the world, and in many geographic regions data are scarce or even nonexistent. This fact hinders the implementation of adequate preventive and therapeutic interventions to reduce the high burden and costs of COPD [1]. In the current study, we have used the Geographic Information System (GIS) inverse distance weighted (IDW) interpolation technique with the objective of visualising spatial data of COPD prevalence in the world and obtaining a visual impression of the magnitude of this global health problem. GIS has been recognised as an effective tool to display the geographical distribution of data, even when they are few and widely separated, as is the case with the prevalence of COPD [2-4].

We conducted a systematic literature search of Medline, EMBASE (via Ovid) and Google Scholar, from January 1995 to March 2019. The search focused on the identification of population-based surveys of COPD prevalence rates conducted in samples representative of the general population among individuals aged $\geqslant 40$ years with airflow limitation compatible with a COPD diagnosis using validated spirometric criteria. The process of article selection and the results of the selected papers have been described in detail in recent publications [5-7]. To complete the original database, data from five other studies published throughout 2018-2019 were added to the previously selected ones [8-12]. Data obtained from the search were analysed using GIS. GIS is a computerised mathematical approach able to extract new information from the available data, using points with known prevalence values to estimate prevalence at other unknown points, finally covering a whole area [3]. The methodology used to develop the GIS maps has been described in detail previously by the authors [5-7]. In brief, the GIS-IDW interpolation computer program uses the prevalence rates obtained from the surveys combined with the geographical coordinates of the places where they were conducted to create raster images with data encoded by pixel values and locations. In the resulting map, blue and green tones represent low values $(\leqslant 8 \%)$; yellow, intermediate (9-15\%); orange, high (16-20\%); red, very high (>20\%); and the sparsely populated areas with fewer than one inhabitant per square kilometre appear shaded in white.
\end{abstract}

The results of the search produced a total of 147 surveys (64 from Europe, 10 from Africa, 17 from the Americas, 53 from Asia and three from Oceania). 18 (12.2\%) surveys used the lower limit of normal and the remaining 129 used the Global Initiative for Chronic Obstructive Lung Disease criteria of a fixed ratio of forced expiratory volume in $1 \mathrm{~s} /$ forced vital capacity $<0.7$. The estimated worldwide COPD mean prevalence (95\% CI) was $13.1 \%$ (10.2-15.6\%), with the following distribution by continents: Europe, $12.4 \%$ (8.8-16.0\%); Africa, 13.9\% (12.0-15.9\%); America, 13.2\% (10.5-15.9\%); Asia, 13.5\% (10.0-16.0\%); and Oceania, $11.6 \%(9.8-13.1 \%)$.

The areas of very high COPD prevalence, represented by intense red shadows, were found in the southwestern extremity of the African continent, with 23\% in Cape Town (South Africa). In the Russian regions of the East European Plain and the Central Siberian Plateau bordering Ukraine, Kazakhstan and Mongolia, the mean prevalence was $21.8 \%$. Finally, the centre of Iran (prevalence 16.9-22.2\%), the region of Nueva Ecija in the Philippines (20.8\%) and some areas of central Europe, such as the Po Delta Area

@ERSpublications

The global prevalence of COPD is $13.1 \%$, ranging from $11.6 \%$ in Oceania to $13.9 \%$ in Africa. With the aid of GIS technology, a global map of prevalence of COPD has been obtained including areas without real data. http://bit.ly/2HRWfK7

Cite this article as: Blanco I, Diego I, Bueno P, et al. Geographic distribution of COPD prevalence in the world displayed by Geographic Information System maps. Eur Respir J 2019; 54: 1900610 [https://doi.org/ 10.1183/13993003.00610-2019]. 


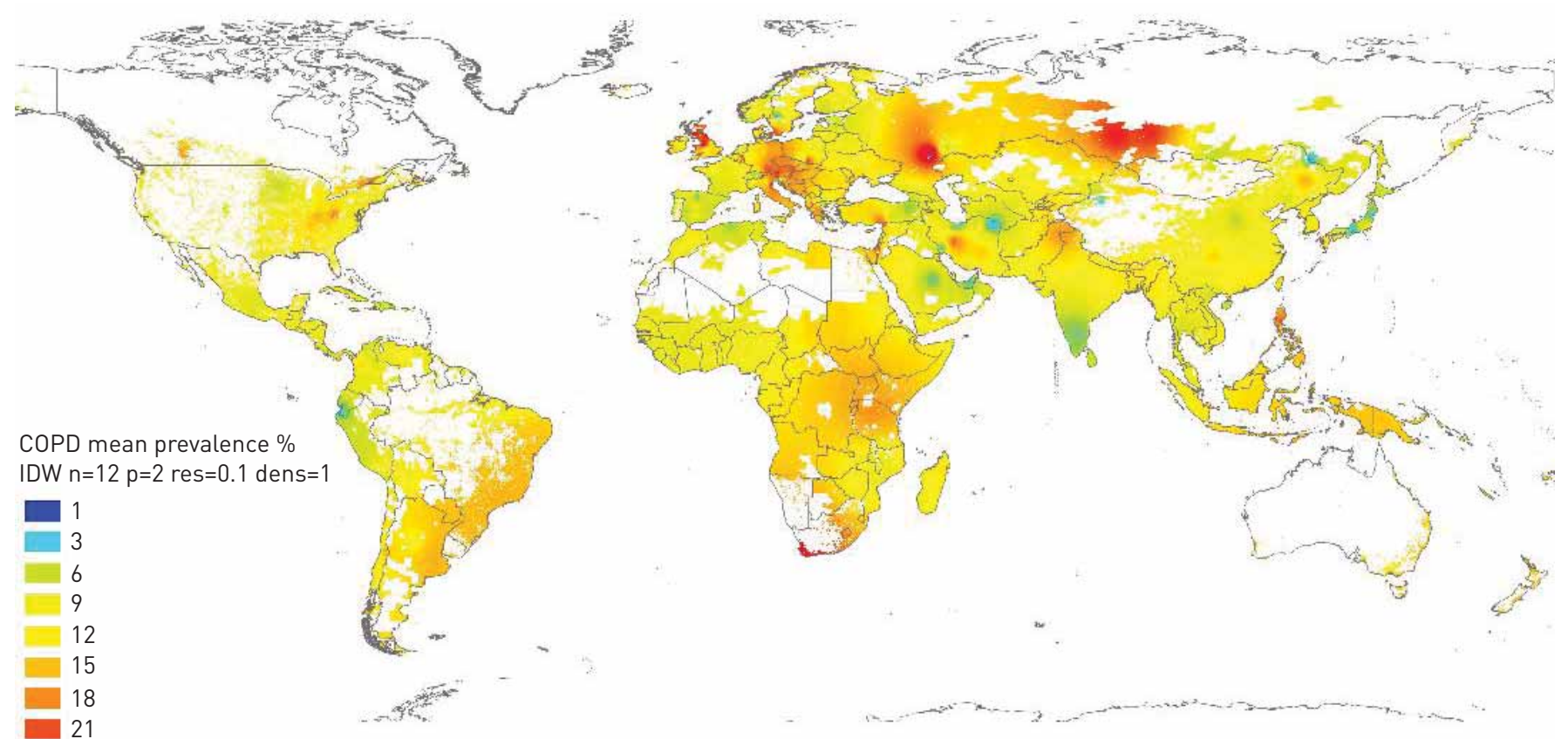

(nverse distance weighted (IDW) interpolation map of chronic obstructive pulmonary disease (COPD) prevalence in and red shadows, indicative of high/very high COPD prevalence, appear in extensive regions of northern and southern Asia; eastern and southern Africa; most regions of Europe; southeast and southwest Canada bordering the USA; in the American regions surrounding the Great Lakes, and the Ohio and the upper Mississippi rivers; and in several coastal areas of Brazil, Uruguay and Argentine bordering the south Atlantic Ocean. Most of the rest of the world regions are shaded in yellow tones indicative of intermediate prevalence. In addition, there are some small areas shaded green and blue due to their low COPD prevalence, as well as several sparsely populated or depopulated areas, scattered across all continents, shaded in white due to lack of data.

(23\%), Salzburg (Austria) (26\%), Munich (Germany) (21\%), and the North of England and Scotland (UK) (Ashington (England) 25\% and Glasgow (Scotland) 24\%), among others, were also shaded in red (figure 1).

Orange shades, indicative of COPD prevalence between $16 \%$ and $20 \%$, covered a large part of Europe and Russia; large regions of central and western Asia, northeastern China, and the Malay Archipelago of southeast Asia. Large areas of Africa and the Americas were also shaded in orange.

Most of the remaining regions of the world were shaded in yellowish tone, indicative of intermediate prevalence (9-15\%). There were several relatively small territories, scattered across all continents, with low COPD prevalence shaded in bluish or greenish tones, including the easternmost regions of north Asia, south India (Bangalore 4.4\%), some areas of the Arabian and the Anatolian peninsulas (Abu Dhabi (United Arab Emirates) 3.7\%, Riyadh (Saudi Arabia) 4.2\% and Erzurum (Turkey) 5\%), and some coastal regions of northwestern South America (Temuco (Chile) $6.4 \%$ and Peru 6\%). Finally, the sparsely populated areas of the world (including Antarctica, northwest Alaska (USA), the Great North of Canada, the Labrador Peninsula (Canada), Greenland, the Amazon basins and their tributary rivers, some areas of the Andean Altiplano and Patagonia, and the various desert and semi-desert lands from all continents) appeared without shading, indicating the lack of reliable epidemiological information.

In a systematic review and meta-analysis published in 2015, Adeloye et al. [13], using the same criteria as in the current study, identified 123 surveys with a global prevalence of COPD in 2010 of $11.7 \%$ (8.4-15.0\%). Interestingly, they observed an increase in prevalence from 1990, when the prevalence observed was $10.7 \%$ (7.3-14.0\%). Our study, including 24 more recent studies, suggests an increase in prevalence up to $13.1 \%$ and confirms the tendency towards a global increase in prevalence of COPD.

Complementing the numbers obtained in our analysis of prevalence, the GIS methodology provides a complete map of all regions of the world, including those without real data. This analysis has limitations related to the epidemiological methods used in the original prevalence studies and to the GIS technique. For example, the data used to compile the database of the GIS program were derived from studies conducted from the 1990s to more recent years [13]. 
GIS is a highly accurate computerised statistical system with mathematical precision [14]. In our study, owing to the scarcity of epidemiological surveys, many geographical regions were shaded by data interpolation using the nearest 12 values of the neighbouring regions of the same country or in some cases, using values of nearby countries. This may have resulted in loss of precision of prevalence estimates for those regions. The GIS method does not take into account ethnic, racial, cultural or political boundaries within and across countries. These factors may be associated with different social habits, languages, inbreeding, nutrition, smoking, occupational and environmental pollutant exposure, and quality of public health services and accessibility to care providers that may modify the prevalence of COPD.

In summary, the present study indicates a global increase in COPD. Because of its ability to present complex data in visually appealing fashion, GIS is a powerful epidemiological tool to convey the current and future epidemiology of COPD and other respiratory diseases [15].

Ignacio Blanco ${ }^{1}$, Isidro Diego $\odot^{2}$, Patricia Bueno ${ }^{3}$, Francisco Casas-Maldonado ${ }^{4}$ and Marc Miravitlles $\odot^{5}$

${ }^{1}$ Alpha1-Antitrypsin Deficiency Spanish Registry (REDAAT), Fundación Respira, Spanish Society of Pneumology and Thoracic Surgery (SEPAR), Barcelona, Spain. ${ }^{2}$ Materials and Energy Dept, School of Mining Engineering, Oviedo University, Oviedo, Spain. ${ }^{3}$ Internal Medicine Dept, County Hospital of Jarrio, Jarrio, Spain. ${ }^{4}$ Pneumology Dept, University Hospital San Cecilio, Granada, Spain. ${ }^{5}$ Pneumology Dept, Hospital Universitari Vall d'Hebron/Vall d'Hebron Research Institute (VHIR), CIBER de Enfermedades Respiratorias (CIBERES), Barcelona, Spain.

Correspondence: Marc Miravitlles, Pneumology Dept, Hospital Universitari Vall d'Hebron/VHIR, Pg. Vall d'Hebron 119-129, 08035, Barcelona, Spain. E-mail: mmiravitlles@vhebron.net.

Received: Nov 192018 | Accepted after revision: April 012019

Author contributions: All the authors have contributed to the elaboration of the manuscript and have approved its final version. I. Blanco, I. Diego and M. Miravitlles are the guarantors of the paper.

Conflict of interest: I. Blanco has nothing to disclose. I. Diego has nothing to disclose. P. Bueno has nothing to disclose. F. Casas-Maldonado has nothing to disclose. M. Miravitlles reports speaker fees from AstraZeneca, Boehringer Ingelheim, Chiesi, Cipla, Menarini, Rovi, Bial, Zambon, CSL Behring, Grifols and Novartis, consulting fees from AstraZeneca, Boehringer Ingelheim, Chiesi, GlaxoSmithKline, Bial, Gebro Pharma, CSL Behring, Laboratorios Esteve, Ferrer, Mereo Biopharma, Verona Pharma, TEVA, pH Pharma, Novartis and Grifols, and research grants from GlaxoSmithKline and Grifols, outside the submitted work.

\section{References}

1 GBD 2015 Chronic Respiratory Disease Collaborators. Global, regional, and national deaths, prevalence, disability-adjusted life years, and years lived with disability for chronic obstructive pulmonary disease and asthma, 1990-2015: a systematic analysis for the Global Burden of Disease Study 2015. Lancet Respir Med 2017; 5: 691-706.

2 Shepard D. A two-dimensional interpolation functions for irregularly-spaced data. In: Proceedings of the 1968 23rd ACM national conference. New York, ACM, 1968; pp. 517-524.

3 McClurg AP, Buss A. Professional development: teachers use of GIS to enhance student learning. J Geog 2007; 106: 79-87.

4 Musa GJ, Chiang P-H, Sylk T, et al. Use of GIS mapping as a public health tool - from cholera to cancer. Health Serv Insights 2013; 6: 111-116.

5 Blanco I, Diego I, Bueno P, et al. Geographical distribution of COPD prevalence in Europe, estimated by an inverse distance weighting interpolation technique. Int J Chron Obstruct Pulmon Dis 2017; 13: 57-67.

6 Blanco I, Diego I, Bueno P, et al. Geographical distribution of COPD prevalence in the Americas. COPD 2018; 15: 317-325.

7 Blanco I, Diego I, Bueno P, et al. Geographic distribution of COPD prevalence in Africa, Asia and Australasia. Int J Tuberc Lung Dis 2019; in press.

8 Broström E, Jõgi R, Gislason T, et al. The prevalence of chronic airflow obstruction in three cities in the NordicBaltic region. Respir Med 2018; 143: 8-13.

9 Bhatta L, Leivseth L, Mai XM, et al. Prevalence and trend of COPD from 1995-1997 to 2006-2008: the HUNT study, Norway. Respir Med 2018; 138: 50-56.

10 Ding Y, Yang D, He P, et al. Prevalence and risk factors of chronic obstructive pulmonary diseases in a Hlai community in Hainan Island of China. Clin Respir J 2018; 12: 126-133.

11 Sharifi $\mathrm{H}$, Ghanei $\mathrm{M}$, Jamaati $\mathrm{H}$, et al. Burden of obstructive lung disease study in Iran: first report of the prevalence and risk factors of COPD in five provinces. Lung India 2019; 36: 14-19.

12 Nightingale R, Lesosky M, Flitz G, et al. Noncommunicable respiratory disease and air pollution exposure in Malawi (CAPS). A cross-sectional study. Am J Respir Crit Care Med 2019; 199: 613-621.

13 Adeloye D, Chua S, Lee C, et al. Global and regional estimates of COPD prevalence: Systematic review and meta-analysis. J Glob Health 2015; 5: 020415.

14 Auchincloss AH, Gebreab SY, Mair C, et al. A review of spatial methods in epidemiology, 2000-2010. Annu Rev Public Health 2012; 33: 107-122.

15 Mitas L, Mitasova H. Geographical information systems: principles, techniques, management and applications. Wiley 1999; 1: 481-492. 